\title{
Modelling the spillover effects of rail passenger crowding on individual well being and organisational behaviour
}

\author{
N. D. Mohd Mahudin ${ }^{1,2}$, T. $\operatorname{Cox}^{1} \&$ A. Griffiths ${ }^{1}$ \\ ${ }^{1}$ Institute of Work, Health and Organisations, \\ University of Nottingham, UK \\ ${ }^{2}$ International Islamic University, Malaysia
}

\begin{abstract}
The challenge of rail passenger crowding has not been fully addressed in the scientific literature. This paper describes a study which explores the relationships among the different psychological components of crowding and their effects on commuters' experience of stress and feelings of exhaustion. The study also considers possible spillover effects in terms of individual and work outcomes. Data were collected from 525 commuters by questionnaire survey and explored using structural equation modelling techniques. The results make clear the relationships among passengers' evaluation of the crowded situation and its ambient environment, their affective reactions to it, and the relationships among these psychological components of passenger crowding and passenger density. The results demonstrate, among other things, the imperfect relationship between the more psychological components of crowding and passenger density. They also reveal different patterns of spillover effects for passenger stress and exhaustion although both affected commuters' report of somatic symptoms of illhealth. In addition, stress spilled over in terms of passengers' propensity for lateness for work but, not in terms of their job or life satisfaction. Exhaustion, in contrast, negatively affected passengers' life satisfaction scores and was a significant predictor of their intention to quit their job. Some theoretical and research implications of these findings are discussed which could lend support for future crowding research and management.

Keywords: rail passenger, crowding, stress, feelings of exhaustion, spillover effects, structural equation modelling.
\end{abstract}




\section{Introduction}

Passenger crowding is a major concern not only for those using rail transport but also for those who manage rail systems worldwide [1]. Many train companies operate with limited systems capacity and with a steadily increasing passenger constituency especially in urban commuting areas. Commuting on a crowded train can be both a time-consuming and a draining experience for passengers, sometimes characterised by stress and frustration [2, 3]. Operating overcrowded trains is a problem for train companies as it may be associated with delays in services, injuries to staff and passengers, wider health and safety issues, as well as being a vehicle for the spread of illness and disease [1, 2, 4]. Despite this, there is insufficient research into the nature and effects of crowding on rail passengers, including commuters [4]. At present, our knowledge is constructed not only from studies on rail travel but also from those involving other forms of transport. It is clear however that the boundaries between the commuting, home and work domains are permeable; the commuting experience can have a detrimental effect on both individual health and organisational behaviour and well-being [1, 2, 5-7]. This has been referred to as "spillover" [8]. In reality, spillover describes a two-way interaction between the commuting experience and more general work and life experiences. Novaco and colleagues, for example, have reported both positive and negative spillover in relation to commuting and the work and life domains $[6,7,9]$.

From a relatively small number of empirical studies, spillover effects of commuting have been found to be associated with a variety of individual work and organisational outcomes, including work-related stress, lost work days, late arrival at work and workplace aggression $[4-6,10]$. Such spillover may also lead to job location change [9]. Additionally, spillover may affect other important aspects of commuters' lives. In a series of studies on the relationship between travel impedance and commuting stress, Novaco et al. $[6,7]$ found that stressful driving conditions can spill over into home life creating a more negative mood at home in the evening. Similarly, Wener and Evans have shown that longer and more arduous commutes are associated with an increasingly greater negative effect on mood [11]. Studies have also suggested gender effects; spillover in terms of the experience of stress arising from congested and lengthy commuting is observed more among women than among men [7, 12].

There are obvious gaps in our current knowledge. First, where crowding has been explored, researchers have tended to focus on its direct effects and less on its potential spillover effects [e.g. 13]. Second, while the spillover effects of tangible commuting factors, such as distance and duration of journey, have been studied [6, 11, 12], the more psychological processes remain relatively unexplored. It is a logical supposition that the experience of stress related to passenger crowding mediates or moderates many of its effects; directly or indirectly. However, the role of the experience of stress has not been extensively studied in this context. Studies elsewhere have consistently demonstrated the adverse effects of crowding on psychological and physiological stress $[14,15]$. The pathways that may link the different components of the passenger crowding 
process have not been explored and therefore made clear beyond the developing work of the current authors [2, 4, 16]. For example, with some exceptions, crowding has been largely ignored as a potential source of commuter stress. Third, and perhaps most disturbing, researchers differ in their views on the definition and construct of crowding as well as on its measurement attributes [for a recent review, see 2]. The study reported here attempts to deal with these three issues. It explores the relationships among the different psychological components of crowding and their direct effects on commuters' experience of stress and feelings of exhaustion. It also so considers possible spillover effects in terms of both individual and work outcomes.

\subsection{Passenger crowding and spillover effects}

The use of the spillover concept is clear in the research of Cox et al. $[1,4]$ in which a working model of passenger crowding, stress, and health and safety is proposed. According to their model, passenger density may lead to perceived crowding although the relationship is imperfect. Perceived crowding may then drive the experience of stress, which, in turn, may result in a multiplicity of outcomes in both individual and work domains. This model assumes that the impact of high passenger density and the perception of crowding on health and safety related outcomes is mediated by the experience of stress and that this overall process is moderated by factors such as perceived control, commute predictability, level of behavioural constraint, level of arousal (activation), and perception of risks. While this model complements existing general theoretical perspectives on crowding [e.g. 14, 15], it also suggests entry points for a variety of practical interventions that might enhance current crowding mitigation measures.

So far, the development of the Cox model has been constrained by a lack of empirical data to test or validate its use as a tool for both understanding passenger crowding and investigating its possible spillover effects. The study described in this paper is one of a series [including 2, 16] which attempts to provide the necessary empirical data to test and develop the model.

\subsection{The nature of crowding}

Most researchers now distinguish between passenger density and perceived crowdedness or crowding [4, 17]. From the work of Kalb and Keating [18], it can be suggested that further distinctions are made between the crowding experience, the essentially psychosocial characteristics of the crowded situation and those of its ambient environment. All three components of crowding, along with passenger density, may have roles to play in determining both its direct and spillover effects. Furthermore, in doing so, there is interplay between the different components. For example, it has been shown that high-density situations may affect both perceived crowding $[1,2,4]$ and induce affective feelings of crowdedness $[14,15]$. This is the approach adopted by Mahudin et al. [16] who have explored this aspect of the Cox et al. model in terms of: commuters' evaluation of the psychosocial aspects of the crowded situation and 
of its ambient environment, their affective experience of crowding and their rating of passenger density.

A number of hypotheses can be advanced on the basis of the Cox model as operationalised here and the supporting literature $[2,4]$.

First, commuters' affective reactions to crowding (their experience of crowding) are determined, at least in part, by their evaluation of the psychosocial aspects of the crowded situation and of its ambient environment and also by rated passenger density.

Second, commuters' affective reactions to crowding will directly determine, at least in part, their report of stress and feelings of exhaustion.

Third, there will be spillover effects of crowding stress and exhaustion on both work and non work outcomes. These will affect individual well-being and satisfaction and organisational behaviour.

The third hypothesis was developed to be more specific about the proposed nature of the spillover effects.

The available evidence suggests that commuting can have adverse physiological, psychological, and behavioural effects on individuals such as raised blood pressure, musculoskeletal discomfort, lowered frustration tolerance, and increased anxiety and hostility, as well as decreased satisfaction with life [5, $6,11]$. The individual aspect of the third hypothesis states that any spillover effects would be made manifest in commuters' reports of somatic symptoms of ill health and decreased life satisfaction.

The available evidence also suggests that spillover may be associated with decreased job satisfaction [4, 5], increased absenteeism [6], and more late arrivals at work as well as higher employee turnover [5]. The work and organisational aspect of the third hypothesis states that any spillover effects would be made manifest in decreased job satisfaction, increased intention to quit (leave their jobs), a greater tendency to be late for work, and increased absenteeism.

\section{Method}

\subsection{Sampling and participants}

Data were collected by questionnaire survey from commuters on four rail lines serving Kuala Lumpur, Malaysia using a proportionate stratified sampling procedure. The four lines involved include two light rail transit and two commuter rail services. The target sample sizes for the rail lines selected were based upon known passenger numbers. In addition, only passengers who commuted to work regularly and frequently were included in the sample. The inclusion criteria were: use of service at least three days each week and use of the same route for at least six months.

A total of 625 respondents participated in this survey; an overall response rate of $89.3 \%$. From this sample pool, 525 respondents met the inclusion criteria and were included for analysis. 
The mean age of the participants was 27.7 years $(\mathrm{SD}=7.3), 63.2 \%$ of respondents were female. The distribution of the sample across lines was $69.5 \%$ using the light rail transit services and $13.7 \%$ using the commuter services. The remaining $16.8 \%$ of the sample was constituted of commuters who normally changed between trains or to other transportation to complete their journeys to work. These sample figures are representative of the user profile of the rail lines selected.

\subsection{Measures}

Rail passenger crowding was measured using a new 20 item scale incorporating three subscales as developed and described by Mahudin et al. [16]: respondents' evaluation of the psychosocial aspects of the crowded situation $(\alpha=.94)$ and of its ambient environment $(\alpha=.87)$, and their affective experience of crowding ( $\alpha$ $=.97)$. Higher scores on the three subscales indicated a more negative response. Passenger density was measured using a pictorial device developed from that used by the UK Rail Safety and Standards Board [19]. Respondents were presented with a scale made up of four pictorial representations of commuters of increasing passenger density. They were asked to use this scale to rate how crowded their commute was.

Passenger stress and feelings of exhaustion were measured using the stress subscale of the Stress and Arousal Checklist [20] and the worn-out subscale of the General Well-Being Questionnaire [20-22] respectively. High scores reflect greater psychological stress and greater mental exhaustion. In the present study, Cronbach's alpha was .81 for the stress subscale and .87 for the worn-out subscale. Both values are only marginally lower than those reported elsewhere: .86 and .88 respectively [e.g. 20,21].

Work spillover was measured using four scales. Job satisfaction was measured using the Minnesota Satisfaction Questionnaire [23], with higher scores reflecting higher job satisfaction. Here, Cronbach's alpha was .94, which is within the range of internal consistency estimates of .87 to .92 reported in other studies [24]. Second, intention to quit was assessed using five items drawn from Crossley et al. [25] and Stinglhamber et al. [26]. The items were summed and a high score indicates a high intention to quit. Cronbach's alpha for this study $(\alpha=.85)$ is only marginally lower that those reported in other studies, for example .89 in Crossley et al. [27]. Third, non-attendance for scheduled work due to the commute was measured by self-reporting the frequency of absence [28]. Higher scores reflect higher levels of absenteeism. Fourth, lateness to work due to the commute was assessed using the average score from a four-item scale adapted from Kluger [29]. Higher scores indicate more frequent lateness. Cronbach's alpha in this study was .60.

Individual spillover effects were measured using the Satisfaction with Life Scale [30]. Cronbach's alpha for life satisfaction was .82, similar to that reported by Pavot and Diener [31]. Somatic symptoms were assessed using items taken from the work of Kluger [29]. Cronbach's alpha for this scale was .59. This was judged to be acceptable although significantly lower than .84, as reported in Kluger's study [29]. 


\subsection{Analysis}

The data collected were subjected to path analysis testing using structural equation modelling (AMOS 16.0) to test the three hypotheses and the overall model. The path analysis approach was undertaken for two reasons: (1) all variables were manifest rather than latent, and (2) the analysis has the capability of assessing complex relationships between multivariate data in a single, systematic and comprehensive analysis [32].

\section{Results}

Table 1 presents the descriptive statistics by variable and correlations among those variables. In the proposed model, correlations among the twelve manifest variables were assumed. The hypotheses were tested using structural equation modelling and the Maximum Likelihood (ML) method was used for the estimation of the model. Before commencing analysis, all variables defining the model were examined for reliability, validity and normality. While the reliability and validity of the model were deemed adequate, the model was significantly kurtotic $($ Mardia's value $=15.126$, critical ratio $=9.454)$. Thus, a bootstrap ML analysis was employed with 500 samples (90\% confidence interval).

The two-step modelling approach of Anderson and Gerbing [33] is usually adopted for model testing. A measurement model is first assessed to test model adequacy followed by full structural modelling examining the causal paths between the latent constructs. Here, no measurement model was computed and assessed because all variables in the proposed model were manifest.

The adequacy of the structural model was estimated using five fit indices: the chi-square goodness-of-fit statistic; the standardised root mean residual (SRMR); the root-mean-square error of approximation (RMSEA); the comparative fit index (CFI); and the parsimonious normed fit index (PNFI). These indices were selected over other indices because they have been found to be the most insensitive to sample size, model misspecification, and parameter estimates [34].

The results for the proposed model are presented in Figure 1 (Note: only statistically significant results are shown in the figure). They showed passenger stress and feelings of exhaustion attributed to crowding, and rated passenger density predicted individual and work outcomes. Although the model yielded a significant chi-square $\left(\chi^{2}(46, \mathrm{~N}=525)=204.727, \mathrm{p}=.001\right)$, a result that is not uncommon with large sample sizes [34], the other indices meet the criteria for adequacy of fit $(\mathrm{SRMR}=.0699 ; \mathrm{RMSEA}=.081 ; \mathrm{CFI}=.927$; PNFI $=.630$; and $\mathrm{AIC}=268.727)$.

The standardised path coefficients support the first hypothesis that the affective reaction to crowding is significantly predicted by commuters' evaluation of the psychosocial aspects of the crowded situation $(\beta=.51, \mathrm{p}<.05)$, by their evaluation of the ambient environment $(\beta=.36, \mathrm{p}<.05)$, and by rated passenger density $(\beta=.13, \mathrm{p}<.05): 79 \%$ of the variance in the affective reaction to crowding is accounted for by the combination of these three predictors. These 


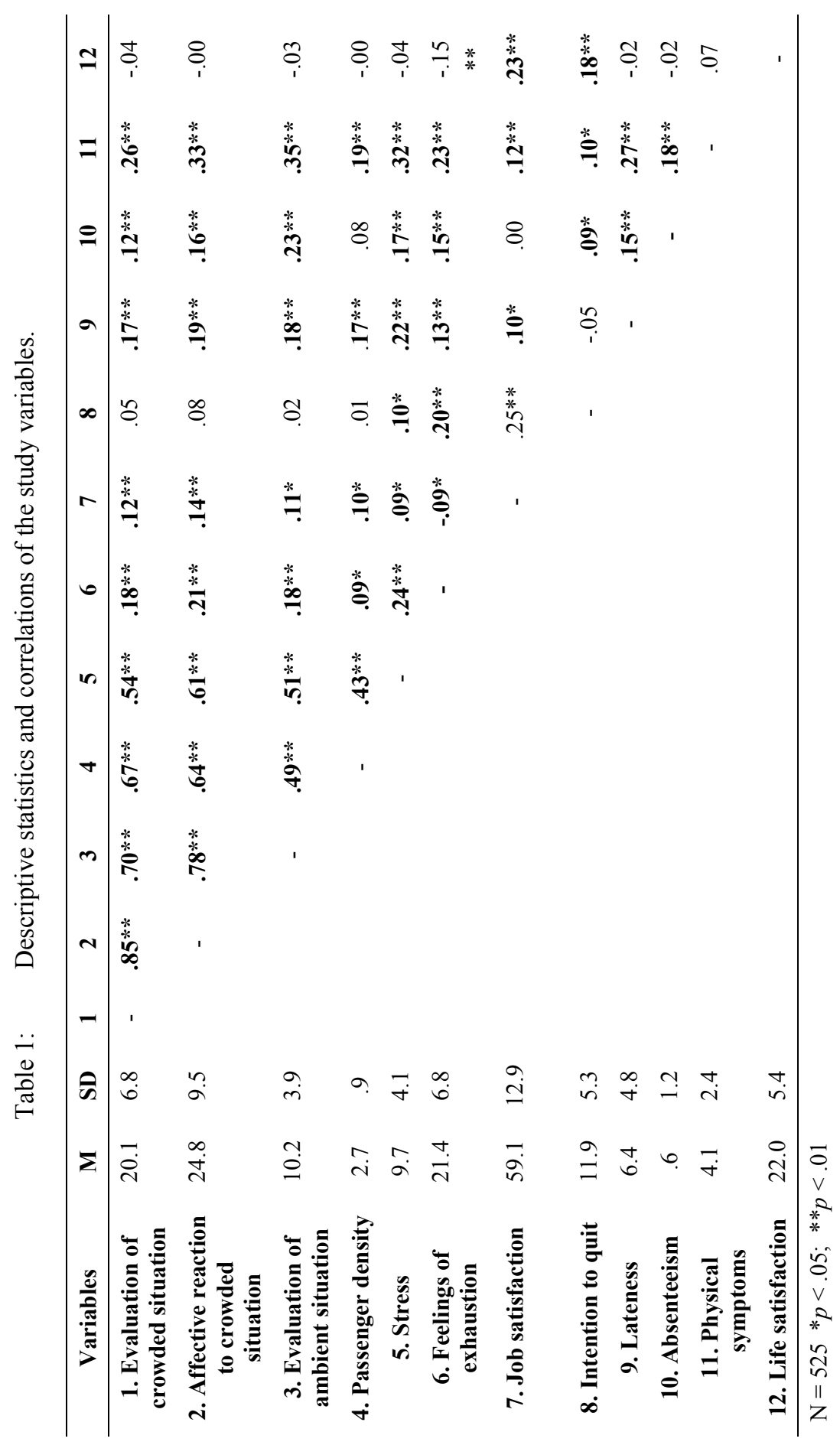




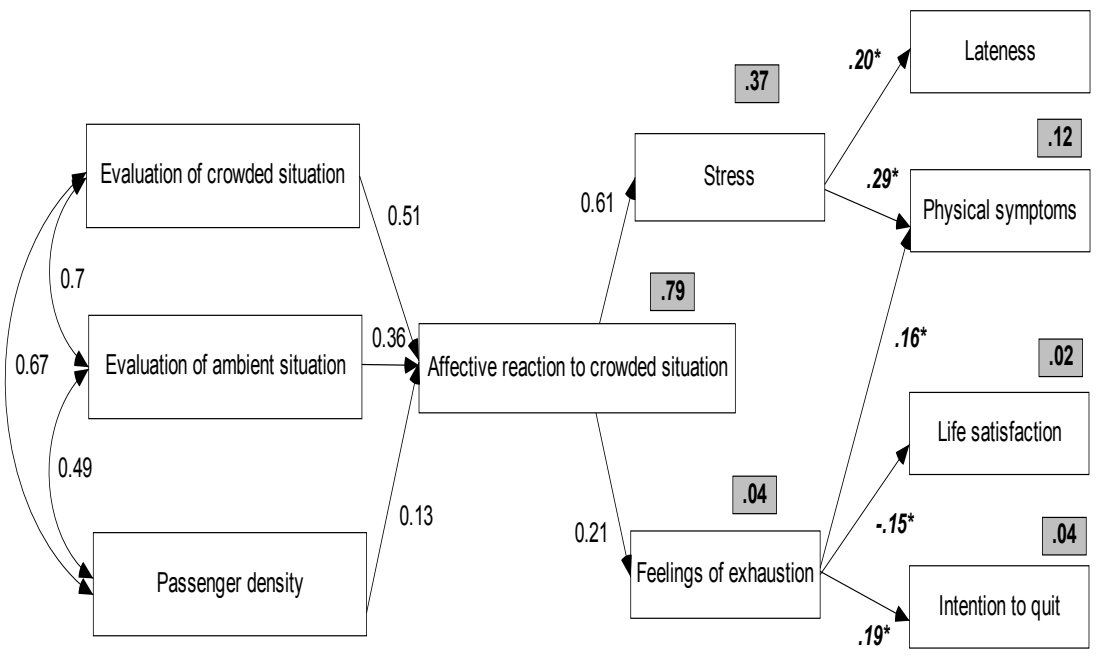

Figure 1: $\quad$ Prediction model.

results also demonstrate the imperfect relationship between the affective reaction to crowding and passenger density $(\beta=.13, \mathrm{p}<.05)$.

The findings also support the second hypothesis that the affective reaction to crowding significantly predicts passenger stress $(\beta=.61, p<.05)$ and feelings of exhaustion $(\beta=.21, \mathrm{p}<.05)$. The more unpleasantly crowded the commuter feels, the more stress and feelings of exhaustion they experience. $37 \%$ of the variance in stress and $4 \%$ in feelings of exhaustion were explained by the affective reaction to crowding.

The findings support and refine the third hypothesis. Passenger stress attributed to crowding predicts the propensity for lateness for work $(\beta=.20, p<$ $.05)$ and reports of somatic symptoms $(\beta=.29, \mathrm{p}<.05)$. However, passenger stress does not significantly predict job satisfaction $(\beta=.12, \mathrm{p}=.007)$, intention to quit $(\beta=.06, \mathrm{p}=.188)$, absenteeism $(\beta=.14, \mathrm{p}=.001)$, or life satisfaction $(\beta$ $=-.003, \mathrm{p}=.95)$.

Passengers' feelings of exhaustion, attributed to crowding, predict somatic symptoms $(\beta=.16, \mathrm{p}<.05)$ and life satisfaction $(\beta=-.15, \mathrm{p}<.05)$ as well as intention to quit $(\beta=.19, \mathrm{p}<.05)$. Feelings of exhaustion, however, do not significantly predict job satisfaction $(\beta=-.12, p=.067)$, absenteeism at work $(\beta$ $=.16, \mathrm{p}=.006)$, or lateness $(\beta=.08, \mathrm{p}=.067)$. The strongest relationship was between commuters' feelings of exhaustion and their report of physical or somatic symptoms $(12.0 \%$ of variance explained). $5.0 \%$ of the variance in lateness for work, $2.1 \%$ of the variance in life satisfaction, $4.2 \%$ of the variance in intention to quit, $2.4 \%$ of the variance in job satisfaction, and $3.7 \%$ of the variance in absenteeism were explained by the combination of passenger stress and feelings of exhaustion. 


\section{Discussion and conclusion}

The study reported here focused on exploring the relationships among the more psychological components of crowding and on testing the existence of spillover effects on both individual and work outcomes. It collected data from 525 commuters in Kuala Lumpur and used structural equation modelling techniques. An overall model was proposed, following from Cox et al. [4] together with three specific hypotheses. The proposed model yielded a good degree of fit to the data and the results of the analysis supported all three hypotheses and allowed the third to be refined. The results demonstrated the imperfect relationship between the affective reaction to crowding and passenger density and confirmed that passenger stress and feelings of exhaustion, attributed to crowding, had the potential to spill over to other aspects of the passengers' life and work. The boundaries between these various domains are indeed permeable.

Commuters reporting higher levels of stress and greater exhaustion, attributed to crowding, also reported more somatic symptoms such as headaches, tension, stiff muscles, and sleeplessness. Spillover effects from passenger stress were also found for work outcomes such as lateness. This latter result is plausible since passengers often let overcrowded trains pass, hoping that the next train will be less crowded. The stress involved in this decision, and in waiting for the next train (not knowing the likely length of wait, hoping it will be less crowded), can therefore be associated with lateness for work. Commuters' feelings of exhaustion were also associated with the report of physical symptoms and were found to negatively affect life satisfaction and intention to quit. These findings are consistent with the limited existing literature $[1,2,4]$.

The processes underpinning effects such as those described above can be explained in terms of contemporary theories of work-related stress [35]. However, an alternative explanation could be offered in terms of crowding being a form of impedance which hinders commuting. Studies by Novaco et al. [6, 7] and Novaco [9], which focus on the inter domain transfer (spillover) effects of travel impedance, argue that traffic congestion can constrain passengers' movement and goal attainment and thus lead to stress and frustration. They suggest that transfer of such effects across different life domains may follow the 'excitation transfer' theory whereby arousal occurring in one domain can transfer to another. This type of explanation might be applied to the effects of passenger crowding.

Taken together, this study has yielded several important findings that strengthen our current understanding of the nature and effects of passenger crowding and point to some new directions for research. The findings, in particular, reinforce the assertion that crowding poses a possible threat to the health of both organisations and passengers as first proposed in the Cox et al. model $[1,4]$. The present study provides empirical evidence supporting that model although the causal evidence for the model is not conclusive. There is sufficient evidence to challenge us to continue research in this area, to develop plausible theoretical explanations of our findings and to apply them managing the challenge of passenger crowding. 
Although our findings show that crowding can pose a significant risk to passenger well-being and to organisational behaviour, the reasons why passengers feel stressed and exhausted by crowded travel conditions need to be explored further. Is it because they feel constrained by the presence of too many other people? Is it because the very nature of commuting places a significant strain upon them, for instance because of services that are unreliable, unpredictable or effortful in nature? The roles of these different psychological and systems variables, which may mediate or moderate reactions to crowded commuting, should be explored further. Rigorous evaluation of the refined frameworks, along with better explanatory and predictive research, should clarify the underlying processes underpinning rail passenger crowding and allow for better management of this challenge.

The Cox et al. model [4] developed further here allows for a variety of interventions that may attenuate both the direct effects of passenger crowding and any spillover effects. Most obvious among these is improving the quality of the ambient environment for the crowded situation. Alongside this, addressing the psychosocial environment as reflected in passengers' evaluation of crowdedness should also help. Of course, reducing the direct effects of crowding should also serve to prevent any spillover effects. Even if engineering or systems solutions are not easily to hand or affordable, there is still much that can be done driven by research such as that reported here.

\section{References}

[1] Cox, T., Griffiths, A. \& Houdmont, J., Rail safety in Britain: An occupational health psychology perspective. Work Stress, 17, pp. 103-108, 2003.

[2] Mohd Mahudin, N.D., Cox, T. \& Griffiths, A., The effects of rail passenger crowding on health and stress: A systematic review. Manuscript submitted for publication, 2010.

[3] Kahneman, D., Krueger, A.B., Schkade, D.A., Schwarz, N. \& Stone, A.A., A survey method for characterizing daily life experience: The day reconstruction method. Science, 306, pp. 1776-1780, 2004.

[4] Cox, T., Houdmont, J. \& Griffiths, A., Rail passenger crowding, stress, health and safety in Britain. Transportation Research Part A - Policy and Practice, 40, pp. 244-258, 2006.

[5] Koslowsky, M., Kluger, A.N. \& Reich, M., Commuting stress. Plenum: New York, 1995.

[6] Novaco, R.W., Stokols, D. \& Milanesi, L., Objective and subjective dimensions of travel impedance as determinants of commuting stress. American Journal of Community Psychology, 18(2), pp. 231-257, 1990.

[7] Novaco, R.W., Kliewer, W. \& Broquet, A., Home environment consequences of commute travel impedance. American Journal of Community Psychology, 19, pp. 881-909, 1991.

[8] Esson, P.L., Consequences of work-family conflict: Testing a new model of work-related, non-work related and stress-related outcomes. Unpublished 
Master's Thesis, Virginia Polytechnic Institute and State University: USA, 2004.

[9] Novaco, R.W., Psychology of transportation. International Encyclopedia of the Social and Behavioral Sciences, pp. 15878-15882, 2001.

[10] Hennessy, D.A., The impact of commuter stress on workplace aggression. Journal of Applied Social Psychology, 38(9), pp. 2315-2335, 2008.

[11] Wener, R.E. \& Evans, G.W., The impact of mode and mode transfer on commuter stress: the Montclair Connection. Final Report No. FHWA-NJ2004-005, 2004, http://www.utrc2.org/research/assets/74/commuterstress2report1.pdf

[12] Wener, R.E., Evans, G.W. \& Boately, P., Commuting stress: Psychophysiological effects of a trip and spillover into the workplace. Transportation Research Record: Journal of Transportation Research Board, 1924, pp. 112-117, 2005.

[13] Evans, G.W. \& Wener, R.E., Crowding and personal space invasion on the train: Please don't make me sit in the middle. Journal of Environmental Psychology, 27, pp. 90-94, 2007.

[14] Baum, A. \& Paulus, P.B., Crowding. Handbook of Environmental Psychology, ed. D. Stokols \& I. Altman, Wiley: New York, pp. 533-570, 1987.

[15] Bell, P., Green, T., Fisher, J. \& Baum, A., Environmental Psychology, Wadsworth Group/Thomson Learning: USA, 2001.

[16] Mohd Mahudin, N.D., Cox, T. \& Griffiths, A., Measuring rail passenger crowding: Scale development and psychometric properties. Manuscript submitted for publication, 2010.

[17] Parsons, K. \& Mohd Mahudin, N.D., Development of a Crowd-Stress Index (CSI) for use in risk assessment. Contemporary Ergonomics, ed. P.T. McCabe, CRC Press: UK, pp. 410-414, 2004.

[18] Kalb, L.S. \& Keating, J.P., The measurement of perceived crowding. Personality and Social Psychology Bulletin, 7, pp. 650-654, 1981.

[19] Rail Safety and Standards Board (RSSB), Crowd management at stations: A good practice guide, Rail Safety and Standards Board: London, 2004.

[20] Cox, T. \& Griffiths, A., The nature and measurement of work-related stress. Evaluation of Human Work: A practical ergonomics methodology, eds. J. Wilson and N Corlett, Taylor \& Francis: London, 2005.

[21] Cox, T., Oliver, A., Rial-González, E., Tomas, J.M., Griffiths, A.J. \& Thompson, L., The development of a Spanish language version of the Worn Out scale of the General Well-Being Questionnaire. Spanish Journal of Psychology, 9, pp. 94-102, 2006.

[22] Cox, T., Thirlaway, M., Gotts, G. \& Cox, S., The nature and assessment of general well-being. Journal of Psychosomatic Research, 27(5), pp. 353359, 1983.

[23] Weiss, D.J., Dawis, R.V., England, G.W. \& Lofquist, L.H., Manual for the Minnesota Satisfaction Questionnaire. University of Minnesota, Industrial Relations Center: Minneapolis, 1967. 
[24] The Assistant Secretary for Planning and Evaluation (ASPE), http://aspe.hhs.gov/daltcp/reports/dcwguideG.pdf

[25] Crossley, C.D., Grauer, E., Lin, L.F. \& Stanton, J.M., Assessing the content validity of intention to quit scales. Proc. of the Annual Meeting of the Society for Industrial and Organizational Psychology, Toronto, Ontario: Canada, 2002.

[26] Stinglhamber, F., Bentein, K. \& Vandenberghe, C., Extension of the threecomponent model of commitment to five foci: Development of measures and substantive test. European Journal of Psychological Assessment, 18(2), pp. 123-138, 2002.

[27] Crossley, C.D., Bennett, R.J., Jex, S.M. \& Burnfield, J.L., Development of a global measure of job embeddedness and integration into a traditional model of voluntary turnover. Journal of Applied Psychology, 92(4), pp. 1031-1042, 2007.

[28] Kessler, R.C., Barber, C., Beck, A.L., Berglund, P.A., Cleary, P.D., McKenas, D., Pronk, N.P., Simon, G.E., Stang, P.E., Üstün, T.B. \& Wang, P.S., The World Health Organization Health and Work Performance Questionnaire (HPQ). Journal of Occupational and Environmental Medicine, 45(2), pp. 156-174, 2003.

[29] Kluger, N., Commute variability and strain. Journal of Organizational Behaviour, 19, pp. 147-165, 1998.

[30] Diener, E., Emmons, R.A., Larsen, R.J. \& Griffin, S., The Satisfaction with Life Scale. Journal of Personality Assessment, 49, pp. 71-75, 1985.

[31] Pavot, W. \& Diener, E., Review of the Satisfaction with Life Scale. Psychological Assessment, 5(2), pp. 164-172, 1993.

[32] Gefen, D., Straub, D. \& Bourdreau, M., Structural equation modeling and regression: Guidelines for research practice. Communications of the Association for Information Systems 4, Article 7, pp. 1-78, 2000.

[33] Anderson, J.C. \& Gerbing, D.W., Structural equation modeling in practice: A review and recommended two-step approach. Psychological Bulletin, 103, pp. 411-423, 1988.

[34] Hooper, D., Coughlan, J. \& Mullen, M.R., Structural equation modelling: Guidelines for determining model fit. The Electronic Journal of Business Research Methods, 6, pp. 53-60, 2008.

[35] Cox, T. \& Griffiths, A., Work-related stress: A theoretical perspective. Occupational Health Psychology, eds. S. Leka and J. Houdmont, WileyBlackwell: Oxford, 2010. 